\title{
Environment, irreversibility and optimal effluent standards*
}

\author{
Jyh-Bang Jou
}

\begin{abstract}
The present article investigates the use of performance standards to correct environmental externalities. Each firm in an industry emits waste in the production process, and, in turn, the average waste emissions of the industry adversely affect the firm's productivity. The firm, which incurs sunk costs when employing capital to abate waste emissions, is uncertain about the efficiency of capital. The firm will underestimate environmental externalities and will therefore pollute more than is socially efficient. To correct this tendency, the regulator can set a limit on either emissions or the emission-output ratio at the socially efficient level. The firm will invest more, produce more, and pollute less when the regulator implements the former than when the regulator implements the latter.
\end{abstract}

\section{Introduction}

Manufacturing firms usually emit waste in the production process. The regulator can induce these firms to employ more abatement capital by implementing command-and-control or market-based instruments. The investment costs on abatement capital, however, are usually sunk (e.g., see Pindyck 2000). ${ }^{1}$ For example, massive sunk costs are needed to switch from coal burning to natural gas burning power plants so as to reduce $\mathrm{CO}_{2}$ emissions (Saphores and Carr 1999). Unlike earlier articles on optimal environmental protection policies (see e.g., Mohtadi 1996), the present article will account for these sunk costs.

The present article compares the use of absolute performance standards (defined as emission limits) with the use of proportional performance

\footnotetext{
* I would like to thank two anonymous reviewers, Tan Lee, and seminar participants at the National Taipei University and the 28th Annual Meeting of the Academy of Economics and Finance held in February 2001.

${ }^{\dagger}$ Jyh-Bang Jou is a professor in the Graduate Institute of National Development, College of Social Science, National Taiwan University.

${ }^{1}$ Costly reversibility may arise because of asset specificity, the lemons problem, or government regulation (Dixit and Pindyck 1994).
} 
standards (defined as a limit on the emission-output ratio) (e.g., see Keohane et al. 1998), both of which can correct environmental externalities. ${ }^{2}$ The present article builds a model in which an industry composed of a fixed number of firms faces a demand function with a constant price elasticity. Each firm's output depends positively on the amount of labour it employs, but negatively on industry's average waste emissions. The firm can employ capital to abate waste emissions, and both the firm and the regulator share the same information about uncertainty regarding the firm's abatement technology. The firm will underestimate environmental externalities because it will ignore the adverse effect of its emissions on other firms' productivity. Therefore, it will pollute more than is socially efficient. To correct this tendency, the regulator can either set an absolute or a proportional performance standard at the socially efficient level. The responses of a firm to these two policies, however, are divergent. The firm will invest more, produce more, and pollute less when the regulator implements the former than when the regulator implements the latter.

The present article is related to the published literature that applies the theory of non-cooperative dynamic games to environmental management such as Haurie and Krawzyck (1997), Haurie and Zaccour (1995), Krawzyck (1995), and Krawzyck and Zaccour (1999). Like these articles, the present article models effluent management as a hierarchical game with a CournotNash equilibrium at the lower level and a Stackelberg equilibrium at the upper level. That is, at the lower level of the game, firms compete for production and investment in a Cournot-Nash type environment. At the upper level of the game, the regulator (i.e., the leader), who anticipates the behavior of a firm (i.e., the follower), sets an efficient level of performance standard accordingly. However, these articles abstract from the investment decision of a firm, and resort to simulation analysis because they construct a more comprehensive model than that constructed in the present article.

Previous studies on performance standards either focus on different issues or adopt assumptions that differ from those made in the present article. For example, a large volume of empirical articles (see e.g., Barbera and McConnell 1986; Gray and Shadbegian 1995) find that performance standards impact on productivity at the firm or plant level, but they ignore the fact that abatement capital may enhance productivity through reducing emissions (as emphasised by the present article). A number of other articles assume that firms are better informed than the regulator, and then rank

\footnotetext{
${ }^{2}$ Several studies on real options either allow government intervention while ignoring externalities (see e.g., Dixit 1991; Dixit and Pindyck 1994; Hassett and Metcalf 1992) or focus on pecuniary rather than production externalities (see e.g., Dixit and Rob 1994; Fatas and Metrick 1997).
} 
policy instruments such as effluent taxes and subsidies, performance standards, and marketable permits (see e.g., Mohtadi 1996; Montero 2002; Requate and Unold 2003; Roberts and Spence 1976; Weitzman 1974). In contrast, the present article abstracts from the issue of asymmetric information.

The present article is also closely related to studies that apply real options to investigate optimal environmental policy, such as Jou (2001). ${ }^{3}$ Jou assumes that a firm's emissions are independent of its output level, and investigates the use of effluent fees to correct environmental externalities. By contrast, the present article assumes that a firm's emissions increase as the firm produces more, and emphasises that the uses of absolute and proportional performance standards may have different impacts on the firm's investment, production, and polluting behavior.

The remaining sections are organised as follows. Section 2 constructs the model and calculates the short-run equilibrium private and social profits. Section 3 allows abatement investment to be either costlessly reversible or completely irreversible. The absolute and proportional performance standards required to support social efficiency for both types of investments are derived. The impacts of several exogenous factors such as uncertainty, costly expandability, and competitive pressure on these two instruments are investigated both analytically and numerically. The last section concludes and suggests extensions for future research.

\section{The Model}

The present article builds a model that incorporates the main features appearing in both the standard real options (see e.g., Dixit 1991) and the environmental economics published literature (see e.g., Cropper and Oates 1992). In the present article, the whole economy is represented by an industry composed of $N$ identical risk-neutral firms facing a demand function with a constant price elasticity $\varepsilon(>0)$; that is,

\footnotetext{
${ }^{3}$ See also Pindyck (2000, 2002), Saphores and Carr (1999), and Xepapadeas (1999). The former three articles consider a regulator who intends to reduce stocks of environmental pollutants once-and-for-all. In Pindyck's two articles, the regulator controls a flow variable that is related to these stocks. In contrast, in Saphores and Carr, the regulator directly controls these stocks. These three articles show that the interaction of irreversibility and uncertainty will affect the regulator's choice of optimal timing to implement policy. While these articles allow the regulator to implement policy just once, the present article allows the regulator to adopt performance standards that may vary over time. The study by Xepapadeas (1999) allows uncertainty in demand, emission tax, and abatement technology, but it does not explicitly model externality nor relate asset characteristics to optimal environmental policies.
} 


$$
Q(t)=P(t)^{-\varepsilon},
$$

where $Q(t)$ is quantity, and $P(t)$ is price. Each firm $i$ in the industry produces final goods according to a Cobb-Douglas technology given by

$$
q_{i}(t)=l_{i}(t) x_{a}(t)^{-\lambda}, \quad \lambda>0,
$$

where $q_{i}(t)$ is firm $i$ 's output, $l_{i}(t)$ is the amount of labour employed by firm $i$, and $x_{a}(t)$, which is industry's average waste emissions, will be strictly positive in industry equilibrium. The adverse effect of $x_{a}(t)$ on $q_{i}(t)$ is external with $\lambda$ measuring its size. This external effect indicates that as firm $i$ emits more, its output as well as the other firms' output will decline. ${ }^{4}$ For example, a firm that emits hazardous pollutants will adversely affect health conditions of the firm's and the other firms' employees. Consequently, the productivity of all firms in the industry will decline. Pollution may also adversely affect the welfare of consumers (see e.g., Cropper and Oates 1992). The present article, however, abstracts from this negative effect. Equation (2) also depicts a case of a uniformly distributed and diffused pollutant, and thus abstracts from both spatial distribution of firms (see e.g., Haurie and Krawzyck 1997) and stock externalities (see e.g., Farzin 1996). Equation (2) is restricted, yet it leads to analytically tractable solutions, and thus simplifies analysis.

By equation (2), firm $i$ does not directly employ any productive capital, but the firm can use capital to abate emissions. ${ }^{5}$ Firm $i$ 's waste emissions, $x_{i}(t)$, are a function of its output, $q_{i}(t)$, its employed abatement capital, $k_{i}(t)$, and a technology-shock factor, $Z(t)$, in the form given by

$$
x_{i}(t)=q_{i}(t)^{\gamma_{1}}\left(k_{i}(t) Z(t)\right)^{-\gamma_{2}}, \quad \gamma_{1}, \gamma_{2}>0 .
$$

Equation (3) indicates that abatement capital exhibits diminishing returns because an increase in abatement capital reduces emissions at a declining rate. The specification in equation (3) also indicates that the amount of waste emitted by firm $i, x_{i}(t)$, is an increasing function of its output, $q_{i}(t)$.

${ }^{4}$ In reality, waste emissions from all industries will have a negative impact on a firm's output in one industry (Ballard and Medema 1993), yet the present article assumes that the whole economy consists of only one industry for ease of exposition.

${ }^{5}$ Some articles on environmental economics allow a firm to employ both productive and abatement capital (see e.g., Kort 1996). The empirical study by Gray and Shadbegian (1998) indicates that these two types of capital tend to crowd out each other. Several articles in published the real options literature also allow two types of capital investment (see e.g., Dixit 1997). However, productive capital is ignored here because including it complicates the analysis while adding little insight into the issue on which the present article focuses. 
The reason is obvious, for example, if steel or electricity production increases, pollution also increases. This specification is more generalised than that in the published literature. For example, Jou (2001) assumes that a firm's emissions are uncorrelated with its output $\left(\gamma_{1}=0\right)$, and Krawzyck (1995) and Xepapadeas (1999) assume that a firm's emissions are proportional to its output (i.e., $\left.\gamma_{1}=1\right)$. The present article, by contrast, allows emissions to be increasing with output at a constant rate, an increasing rate (i.e., $\gamma_{1}>1$ ), or a decreasing rate (i.e., $\gamma_{1}<1$ ).

In equation (3), the factor $Z(t)$ exhibits a negative correlation with $x_{i}(t)$, indicating that abatement capital is more efficient in good states of the world (i.e., when $Z(t)$ is higher). The factor $Z(t)$, which is required to be positive so as to ensure that firm $i$ 's waste emissions given by equation (3) are positive, is assumed to evolve as geometric Brownian motion with no drifts:

$$
d Z(t)=\sigma Z(t) d \Omega(t)
$$

where $\sigma(>0)$ is the instantaneous volatility of the growth rate of $Z(t)$, and $d \Omega(t)$ is an increment to a standard Wiener process, with $E\{d \Omega(t)\}=0$ and $E\{d \Omega(t)\}^{2}=d t$. By the standard theory of Brownian motion, we know that $Z(t)$ has a lognormal distribution with mean $Z(0)$ and variance $Z(0)^{2}\left(e^{\sigma^{2} t}-1\right){ }^{6}$

Equation (4) indicates that information about the evolution of a firm's waste emissions arriving in time is independent of its investment decision. This contrasts with that of Kolstad (1996) where uncertainty can be resolved over time through learning. Equation (4) also indicates a case of symmetric information between a firm and the regulator regarding the efficiency of abatement capital because both regard $Z(t)$ as exogenously given. ${ }^{7}$ The case of asymmetric information is considered in the standard published environmental economics literature - see Jung et al. (1996), Requate and Unold (2003), and Weitzman (1974). These articles, however, focus on ranking various policy instruments including effluent taxes and subsidies, performance standards, and marketable permits. The published real options literature that incorporates this issue includes Gaudet et al. (1998), which, however, does not allow environmental externalities.

${ }^{6}$ Equation (3) indicates that I do not allow new abatement capital to be more efficient than old capital. One alternative way to take this into consideration is to replace $k_{i}(t)$ by $a(t) k_{i}(t)$, where $d a(t) / d t \geq 0$, indicating that there is technological progress.

\footnotetext{
7 The present article allows a firm to adopt only one type of abatement capital. One may assume that a firm chooses between an old and a new abatement technique, and then follows the solution method in Dixit (1991) to solve the firm's choice. The qualitative results of the present article, however, will not be affected even though such a choice is allowed.
} 
Suppose that $q(t)=\left(q_{1}(t), \ldots, q_{N}(t)\right)$ and $k(t)=\left(k_{1}(t), \ldots, k_{N}(t)\right)$. The operating profit flow of firm $i$, denoted by $\pi_{i}^{1}(q(t), k(t), Z(t))$, is equal to its operating revenue $P(t) q_{i}(t)$, minus its variable cost denoted by $C_{i}^{1}(q(t), k(t)$, $Z(t))$ in equation (6) below, thus yielding

$$
\pi_{i}^{1}(q(t), k(t), Z(t))=P(t) q_{i}(t)-C_{i}^{1}(q(t), k(t), Z(t)) .
$$

Denote $w$ as a given wage rate. By equation (2), firm $i$ 's variable cost, $w l_{i}(t)$, is given by

$$
C_{i}^{1}(q(t), k(t), Z(t))=w q_{i}(t) x_{a}(t)^{\lambda}
$$

where $x_{a}(t)=\left(\sum_{j=1}^{N} q_{j}(t)^{\gamma_{1}}\left(k_{j}(t) Z(t)\right)^{-\gamma_{2}}\right) / N$.

Following the published literature applying non-cooperative dynamic games to environmental management (see e.g., Haurie and Krawzyck 1997; Haurie and Zaccour 1995; Krawzyck 1995; Krawzyck and Zaccour 1999), the present article models effluent management as a hierarchical game with a Cournot-Nash equilibrium at the lower level where firms compete for production and investment. At the upper level of the game, the regulator acts as the leader and a firm acts as the follower. The regulator should anticipate the production and investment behavior of the firm, and then set performance standards at the socially efficient level accordingly.

In Cournot-Nash short-run equilibrium, firm $i$ will take all the other firms' production strategies as given, while choosing an output level, denoted by $q_{i}^{1}(t)$, to maximise its operating profit, $\pi_{i}^{1}(\cdot)$ given by equation (5). Consequently, $q_{i}^{1}(t)$ is derived by setting the derivative of $\pi_{i}^{1}(\cdot)$ with respect to $q_{i}(t)$ equal to zero. This yields the equality of marginal revenue with shortrun marginal cost as given by

$$
P(t)\left(1-\left(\frac{q_{i}(t)}{\varepsilon Q(t)}\right)\right)=w x_{a}(t)^{\lambda-1}\left(x_{a}(t)+\frac{\lambda \gamma_{1} x_{i}(t)}{N}\right) .
$$

Imposing the short-run equilibrium condition $q_{j}(t)=q_{i}^{1}(t)(j=1, \ldots, N)$ in (7) yields $q_{i}^{1}(t)$ and its corresponding $P^{1}(t)$ :

$$
\begin{aligned}
q_{i}^{1}(t) & =\left[w\left(1-\frac{h}{N}\right)^{-1} N^{h-\lambda} Z(t)^{-\lambda \gamma_{2}} G_{1}^{\lambda-1}\left(G_{1}+\lambda \gamma_{1} k_{i}(t)^{-\gamma \gamma_{2}}\right)\right]^{\frac{-1}{\left(\lambda \gamma_{1}+h\right)}}, \\
P^{1}(t) & =\left(N q_{i}^{1}(t)\right)^{-h},
\end{aligned}
$$


where $h=1 / \varepsilon$ and $G_{1}=\sum_{j=1}^{N} k_{j}(t)^{-\gamma_{2}}$. Evaluating $\pi_{i}^{1}(\cdot)$ in equation $(5)$ at $q_{j}(t)=$ $q_{i}^{1}(t)(j=1, \ldots, N)$ yields the optimised value of firm $i$ 's operating profit, denoted by $\pi^{1}(k(t), Z(t))$, as given by

$$
\pi^{1}(k(t), Z(t))=B_{1} G_{1}^{a_{1}} G_{2}^{\frac{-\left(\lambda \gamma_{1}+1\right)}{\left(\lambda \gamma_{1}+h\right)}} G_{3} Z(t)^{a_{0}},
$$

where $a_{0}=\frac{\lambda \gamma_{2}(1-h)}{\left(\lambda \gamma_{1}+h\right)}, \quad a_{1}=\frac{(1-\lambda)(1-h)}{\left(\lambda \gamma_{1}+h\right)}, \quad G_{2}=G_{1}+\lambda \gamma_{1} k_{i}(t)^{-\gamma_{2}}, \quad G_{3}=\frac{h}{N} G_{1}$ $+\lambda \gamma_{1} k_{i}^{-\gamma_{2}}, \quad B_{1}=w^{\frac{h-1}{\left(\lambda \gamma_{1}+h\right)}}\left(1-\frac{h}{N}\right)^{\frac{(1-h)}{\left(\lambda \gamma_{1}+h\right)}} N^{-\lambda+\frac{\left(\lambda \gamma_{1}+1\right)(\lambda-h)}{\left(\lambda \gamma_{1}+h\right)}}$.

In contrast, a social planner will internalise environmental externalities before producing final goods. The social planner perceives that firm $i$ 's emissions, $x_{i}(t)$, are equal to the industry's average emissions, $x_{a}(t)$, because all firms are identical. By equation (3), this also implies that the central planner will impose $q_{j}(t)=q_{i}(t)$ and $k_{j}(t)=k_{i}(t)(j=1, \ldots, N)$ before producing final goods. The operating profit of firm $i$ perceived by the social planner, denoted by $\pi_{i}^{2}\left(q_{i}(t), k_{i}(t), Z(t)\right)$, is equal to operating revenue $P(t) q_{i}(t)$ minus the variable cost of firm $i$ perceived by the social planner, denoted by $C_{i}^{2}\left(q_{i}(t), k_{i}(t), Z(t)\right)$ in equation (11) below, thus yielding

$$
\pi_{i}^{2}\left(q_{i}(t), k_{i}(t), Z(t)\right)=P(t) q_{i}(t)-C_{i}^{2}\left(q_{i}(t), k_{i}(t), Z(t)\right) .
$$

By equation (2) and the condition $x_{a}(t)=x_{i}(t)$, the variable cost of firm $i$ perceived by the social planner, $w l_{i}(t)$, is given by

$$
C_{i}^{2}\left(q_{i}(t), k_{i}(t), Z(t)\right)=w q_{i}(t) x_{i}(t)^{\lambda} .
$$

The social planner will choose an output level, denoted by $q_{i}^{2}(t)$, to maximise firm $i$ 's operating profit, $\pi_{i}^{2}(\cdot)$ given by equation (11). Consequently, $q_{i}^{2}(t)$ is derived by setting the derivative $\pi_{i}^{2}(\cdot)$ with respect to $q_{i}(t)$ equal to zero. This yields the equality given by

$$
P(t)\left(1-\frac{1}{\varepsilon}\right)=\left(1+\lambda \gamma_{1}\right) w q_{i}(t)^{\lambda \gamma_{1}}\left(k_{i}(t) Z(t)\right)^{-\lambda \gamma_{2}}
$$

where $\varepsilon$ is required to be larger than one (and thus $h=1 / \varepsilon<1$ ) so as to ensure that marginal revenue is positive. Imposing the condition $q_{j}(t)=q_{i}^{2}(t)$ 
$(j=1, \ldots, N)$ in equation (13) yields $q_{i}^{2}(t)$ and its corresponding $P^{2}(t)$ as given by

$$
\begin{aligned}
& q_{i}^{2}(t)=\left[\left(1+\lambda \gamma_{1}\right) w(1-h)^{-1} N^{h}\left(k_{i}(t) Z(t)\right)^{-\lambda \gamma_{2}}\right]^{\frac{-1}{\left(\lambda \gamma_{1}+h\right)}}, \\
& P^{2}(t)=\left(N q_{i}^{2}(t)\right)^{-h} .
\end{aligned}
$$

Evaluating $\pi_{i}^{2}(\cdot)$ in equation (11) at $q_{i}(t)=q_{i}^{2}(t)$ yields the optimised value of $\pi_{i}^{2}(\cdot)$, denoted by $\pi^{2}\left(k_{i}(t), Z(t)\right)$, as given by

$$
\pi^{2}\left(k_{i}(t), Z(t)\right)=B_{2} k_{i}(t)^{a_{0}} Z(t)^{a_{0}},
$$

where $B_{2}=\left(\lambda \gamma_{1}+h\right)[(1-h) / w]^{\frac{(1-h)}{\left(\lambda \gamma_{1}+h\right)}}\left[N^{h}\left(1+\lambda \gamma_{1}\right)\right]^{\frac{-\left(\lambda \gamma_{1}+1\right)}{\left(\lambda \gamma_{1}+h\right)}}$.

\section{Efficient performance standards}

When industry pollution exhibits negative externalities as shown by equation (2), then market outcomes will be inefficient. The policy to correct this includes market-based instruments or command-and-control regulations. Market-based instruments, however, are still not popular: the application of tradable permits appeared in few countries such as Australia, Canada, Chile, and the USA (see e.g., Gomboso et al. 1999), and effluent fees (and subsidies) adopted by Europe have been set at very low levels, and thus are usually not considered as an effective way to control pollution (Kolstad, 2000). Command-and-control regulations, which are still the dominant form of environmental regulation in the world today, have two major types: technologyand performance-based standards (Stavins 2000). Technology-based standards specify the method and/or the equipment (the so-called best available control technology) that firms must use to comply with a particular regulation. In the USA, the specific technologies are usually determined by states on a case-by-case basis. However, the USA has established national emission standards for new sources of pollutants, called the New Source Performance Standards (Tietenberg 1992, p. 397). In the present article I focus on performance standards, which could specify an absolute quantity of permissible emissions, but more typically these standards establish allowable emissions in proportional to output (Keohane et al. 1998). In what follows, I will investigate both types of performance standards, while abstracting from the auditing and administrative costs associated with implementing them.

For ease of exposition, I will abstract from capital depreciation and also assume that the purchasing and installation price of abatement capital, denoted by $P_{K}(t)$, grows at a constant rate $\mu$; that is, 


$$
d P_{K}(t)=\mu P_{K}(t) d t
$$

A firm is in an environment where it is costly to expand capacity later when $\mu$ is positive. ${ }^{8}$ The following analysis, however, is suitable for both positive as well as non-positive values of $\mu$. Two types of investments are considered: (i) investment is costlessly reversible where the resale price of abatement capital is equal to the purchase price of capital; ${ }^{9}$ and (ii) investment is completely irreversible where the resale price of abatement capital is equal to zero.

\subsection{Costlessly reversible investment}

Suppose that investment is costlessly reversible. Then $k_{i}(t)$ will be a choice rather than a state variable. Let $\rho$ denote a given (risk-adjusted) discount rate. The abatement capital stock chosen by firm $i$ at each instant will be found by equating the private marginal return to capital with the user cost of capital (i.e., the rental cost of abatement capital net of capital gain) (Jorgenson 1963); that is,

$$
\frac{\partial \pi^{1}(k(t), Z(t))}{\partial k_{i}(t)}=(\rho-\mu) P_{K}(t)
$$

where $\pi^{1}(k(t), Z(t))$ is given by equation (16). In Cournot-Nash equilibrium, all firms will choose an equal amount of abatement capital, denoted by $k_{f 1}^{u}(t)$, where the subscript ' $u$ ' denotes the situation where no regulation is imposed. Substituting this condition into equation (18) and then rearranging yields

$$
k_{f 1}^{u}(t)=\left[\left(\left(1-\frac{h}{N}\right)\left(1+\frac{\lambda \gamma_{1}}{N}\right)^{-1}\right)^{\frac{\lambda \gamma_{1}+1}{\left(\lambda \gamma_{1}+h\right)}} \frac{(N-h)^{-1} H Z(t)^{a_{0}}}{(\rho-\mu) P_{K}(t)}\right]^{\frac{1}{1-a_{0}}},
$$

${ }^{8}$ This may arise because of limited land, natural resource reserves, or the need for a permit that is in short supply (Dixit and Pindyck, 1998).

${ }^{9}$ One may allow the installed abatement capital to have some resale value. Under such a situation, in addition to effluent standard restrictions, the regulator may add one more policy instrument such as a tax on disinvestment. Such an extension, however, will not alter the main results of the present article. See, for example, the article by Jou and Lee (2001) where R\&D capital exhibits positive production externalities and partial irreversibilities, and the regulator gives investment tax credits when $R \& D$ capital is purchased, but imposes taxation when the installed R\&D capital is sold. 
where $H=\lambda \gamma_{2}(1-h) w^{\frac{h-1}{\left(\lambda \gamma_{1}+h\right)}} N^{\frac{-h\left(\lambda \gamma_{1}+1\right)}{\left(\lambda \gamma_{1}+h\right)}} \cdot{ }^{10}$ Here and in what follows, I will assume that $\rho>\mu$ so as to ensure that demand for abatement capital is decreasing with the price of capital; that is, $k_{f 1}^{u}(t)$ given by equation (19) is decreasing with $P_{K}(t)$. Substituting $k_{j}(t)=k_{f 1}^{u}(t)(j=1, \ldots, N)$ into equation (8) yields the choice of output for firm $i$ without any regulation, denoted by $q_{f 1}^{u}(t)$ :

$$
q_{f 1}^{u}(t)=A_{1} k_{f 1}^{u}(t)^{\frac{\lambda \gamma_{2}}{\left(\lambda \gamma_{1}+h\right)}} Z(t)^{\frac{\lambda \gamma_{2}}{\left(\lambda \gamma_{1}+h\right)}}
$$

where $A_{1}=\left[\left(1+\frac{\lambda \gamma_{1}}{N}\right) w\left(1-\frac{h}{N}\right)^{-1} N^{h}\right]^{\frac{-1}{\left(\lambda \gamma_{1}+h\right)}}$. Substituting $q_{i}(t)=q_{f 1}^{u}(t)$ and $k_{i}(t)=k_{f 1}^{u}(t)$ into equation (3) yields the choice of emission for firm $i$ without any regulation, denoted by $x_{f 1}^{u}(t)$ :

$$
x_{f 1}^{u}(t)=A_{1}^{\gamma_{1}} k_{f 1}^{u}(t)^{\frac{-\gamma_{2} h}{\left(\lambda \gamma_{1}+h\right)}} Z(t)^{\frac{-\gamma_{2} h}{\left(\lambda \gamma_{1}+h\right)}} .
$$

Similarly, the capital stock chosen by a social planner at each instant, denoted by $k_{f 2}(t)$, is found by equating the social marginal return to capital with the user cost of capital; that is,

$$
\frac{\partial \pi^{2}\left(k_{i}(t), Z(t)\right)}{\partial k_{i}(t)}=(\rho-\mu) P_{K}(t)
$$

where $\pi^{2}(\cdot)$ is given by equation (16). Evaluating equation (22) at $k_{i}(t)=k_{f 2}(t)$, and then rearranging yields

$$
k_{f 2}(t)=\left[\left((1-h)\left(1+\lambda \gamma_{1}\right)^{-1}\right)^{\frac{\lambda \gamma_{1}+1}{\left(\lambda \gamma_{1}+h\right)}} \frac{(1-h)^{-1} H Z(t)^{a_{0}}}{(\rho-\mu) P_{K}(t)}\right]^{\frac{-1}{1-a_{0}}} .
$$

Substituting $k_{i}(t)=k_{f 2}(t)$ into equation (14) yields the social planner's choice of output, denoted by $q_{f 2}(t)$ :

\footnotetext{
${ }^{10}$ One may rigorously show that all Cournot-Nash equilibria considered here and in what follows are unique. See, for example, Grenadier (2002), Haurie and Zaccour (1995), and Rosen (1965).
} 


$$
q_{f 2}(t)=A_{2} k_{f 2}(t)^{\frac{\lambda \gamma_{2}}{\left(\lambda \gamma_{1}+h\right)}} Z(t)^{\frac{\lambda \gamma_{2}}{\left(\lambda \gamma_{1}+h\right)}}
$$

where $A_{2}=\left[\left(1+\lambda \gamma_{1}\right) w(1-h)^{-1} N^{h}\right]^{\frac{-1}{\left(\lambda \gamma_{1}+h\right)}}$. Substituting $q_{i}(t)=q_{f 2}(t)$ and $k_{i}(t)$ $=k_{f 2}(t)$ into equation (3) yields the choice of emission by the social planner, denoted by $x_{f 2}(t)$ :

$$
x_{f 2}(t)=A_{2}^{\gamma_{1}} k_{f 2}(t)^{\frac{-\gamma_{2} h}{\left(\gamma_{1}+h\right)}} Z(t)^{\frac{-\gamma_{2} h}{\left(\lambda \gamma_{1}+h\right)}} .
$$

\subsection{Irreversible investment}

In the long-run, through Cournot-Nash competition, firm $i$ will maximise the expected discounted private profit flow net of the investment costs. Suppose that $V_{1}\left(k(t), Z(t), P_{K}(t)\right)$ denotes the value function for firm $i$, which is given by

$$
V_{1}(\cdot)=\max _{\left\{I_{i}(t)\right\}} E_{t}\left\{\int_{t}^{\infty} e^{-\rho(\tau-t)}\left[\pi^{1}(k(\tau), Z(\tau))-P_{K}(\tau) I_{i}(\tau)\right] d \tau\right\},
$$

where the state equation for $k_{i}(\tau)$ is given by

$$
I_{i}(\tau)=\frac{d k_{i}(\tau)}{d \tau}
$$

$I_{i}(\tau)$ is also the gross investment rate for firm $i$ at time $\tau, \pi^{1}(\cdot)$ is given by equation (10), $\rho$ is the discount rate, and $E_{t}\{\cdot\}$ denotes the conditional expectation taken at time $t$. The maximisation problem faced by firm $i$ includes $N+2$ state variables: $Z(t), P_{K}(t)$, and an n-tuple of strategies, $k(t)$. Firm $i$ will treat $Z(t), P_{K}(t)$ and $k_{-i}(t)=\left(k_{1}(t), \ldots, k_{i-1}(t), k_{i+1}(t), \ldots, k_{N}(t)\right)$ as exogenously given, while controlling $I_{i}(t)$. However, all elements of $k_{-i}(t)$ should be equal to $k_{i}(t)$ in Cournot-Nash equilibrium.

As is well known in the published real options literature, the interaction of the stochastic evolution of $Z(t)$ and investment irreversibility indicates that firm $i$ solves a problem of instantaneous control of Brownian motion. The optimal policy is to regulate the state variable $k_{i}(t)$ at a lower barrier, denoted by the desired capital stock $k_{i^{*}}(t)$ (Bertola and Caballero 1994). If the currently installed capital $k_{i}(t)$ is smaller than $k_{i^{*}}(t)$, firm $i$ should invest so as to obtain $k_{i}(t)=k_{i^{*}}(t)$; otherwise no action should be taken. Firm $i$ should form expectations about the distant future regarding when and how much to invest because irreversible investment decisions will affect future 
cash flows: firm $i$ may be stuck with an excessive stock of capital in the initial period as pointed out by Clark et al. (1979), and Bertola and Caballero (1994). Given the abatement technology shown by equation (3), it is equivalent to saying that firm $i$ should regulate its pollution, $x_{i}(t)$ in equation (3), at an upper barrier, denoted by $x_{i}^{*}(t)$. Consequently, $x_{i}^{*}(t)$ is also the maximum amount of waste emissions tolerable by firm $i$.

Define $G_{4}=\sum_{j=1}^{N} k_{j}(t)^{-\gamma_{2}-1}, G_{5}=G_{4}+\lambda \gamma_{1} k_{i}(t)^{-\gamma_{2}-1}$, and $G_{6}=h G_{4} / N+\lambda \gamma_{1} k_{i}^{-\gamma_{2}-1}$. When $k_{i}(t)>k_{i^{*}}(t)$, the private marginal gain from increasing the abatement capital stock, $v_{1}(\cdot)=\partial V_{1}(\cdot) / \partial k_{i}(t)$, is given by (see Appendix)

$$
v_{1}(\cdot)=F_{1}\left[G Z(t)^{a_{0}}\right]^{\beta} P_{K}(t)^{1-\beta}+G Z(t)^{a_{0}} / \phi(1),
$$

where

$$
G=\gamma_{2} B_{1} G_{1}^{a_{1}-\frac{\left(\lambda \gamma_{1}+1\right)}{\left(\lambda \gamma_{1}+h\right)}-1}\left[-a_{1} G_{2} G_{3} G_{4}-G_{1} G_{2} G_{6}+\frac{\left(\lambda \gamma_{1}+1\right)}{\left(\lambda \gamma_{1}+h\right)} G_{1} G_{3} G_{5}\right],
$$

$F_{1}$ is a constant to be determined, $\beta$ is the larger root of $\tau$ in the quadratic equation given by equation (56), and $\phi(1)$ is obtained by setting $\tau=1$ in equation (57). On the right-hand side of equation (28), the first term is the private value of the option to install an additional unit of capital, while the second term is the private value of the last incremental unit of installed capital. Two optimal conditions must be satisfied at $k_{i}(t)=k_{i^{*}}(t)$ (Pindyck 1988). First, the private marginal gain from increasing the capital stock must equal its marginal costs at the instant of investing (see equation (53) in Appendix); that is,

$$
v_{1}(\cdot)=P_{K}(t)
$$

This is the value-matching condition. Second, the equality given by equation (29) must be satisfied at the states both just before and just after the investment, thus yielding

$$
\frac{\partial v_{1}(\cdot)}{\partial Z(t)}=0
$$

This is the smooth-pasting condition.

The $k_{i}(t)$ desired by firm $i$ when investment is completely irreversible without any regulation, denoted by $k_{s 1}^{u}(t)$, is solved from the procedures as follows. First, evaluate both equation (29) and equation (30) at $k_{i}(t)=$ $k_{s 1}^{u}(t)$. Second, multiply equation $(30)$ by $Z(t) /\left(a_{0} \beta\right)$, and then add the 
result into equation (29). Third, use the value of $\phi(1)$ given by equation (57). Finally, impose the equilibrium condition $k_{j}(t)=k_{s 1}^{u}(t)(j=1, \cdots, N)$. The result is

$$
k_{s 1}^{u}(t)=m_{1} k_{f 1}^{u}(t), \text { where } m_{1}=[\alpha /(1+\alpha)]^{1 /\left(1-a_{0}\right)},
$$

where $-\alpha$ is the smaller root of $\tau$ in the quadratic equation given by equation (56), and $k_{f 1}^{u}(t)$ is given by equation (19). Substituting $k_{i}(t)=k_{f 1}^{u}(t)$ into equation (8) yields the maximum level of output produced by firm $i$, denoted by $q_{s 1}^{u}(t)$ :

$$
q_{s 1}^{u}(t)=A_{2} k_{s 1}^{u}(t)^{\frac{\lambda \gamma_{2}}{\left(\lambda \gamma_{1}+h\right)}} Z(t)^{\frac{\lambda \gamma_{2}}{\left(\lambda \gamma_{1}+h\right)}}=m_{2} q_{f 1}^{u}(t) \text {, where } m_{2}=[\alpha /(1+\alpha)]^{\frac{1}{\gamma_{1}}-1+h\left(1+\frac{1}{\lambda \gamma_{2}}\right)} .
$$

Substituting both $q_{i}(t)=q_{s 1}^{u}(t)$ and $k_{i}(t)=k_{s 1}^{u}(t)$ into equation (3) yields the maximum amount of waste emissions tolerable by firm $i$, denoted by $x_{s 1}^{u}(t)$ :

$$
x_{s 1}^{u}(t)=A_{1}^{\gamma_{1}} k_{s 1}^{u}(t)^{\frac{-\gamma_{2} h}{\left(\lambda \gamma_{1}+h\right)}} Z(t)^{\frac{-\gamma_{2} h}{\left(\gamma_{1}+h\right)}}=m_{3} x_{f 1}^{u}(t) \text {, where } m_{3}=[1+1 / \alpha]^{\frac{1}{\frac{\lambda}{\left(\frac{\gamma_{1}}{\gamma_{2}}-1+h\right)+\frac{1}{\gamma_{2}}}}} .
$$

Similarly, suppose that $V_{2}\left(k_{i}(t), Z(t), P_{k}(t)\right)$ denotes the value function for firm $i$ perceived by the social planner, which is given by

$$
V_{2}(\cdot)=\max _{\left\{I_{i}(\tau)\right\}} E_{t}\left\{\int_{t}^{\infty} e^{-\rho(\tau-t)}\left[\pi^{2}(k(\tau), Z(\tau))-P_{K}(\tau) I_{i}(\tau)\right] d \tau\right\}
$$

where $\pi^{2}(\cdot)$ is given by equation (16). The maximisation problem faced by the social planner includes three state variables: $Z(t), P_{K}(t)$, and $k_{i}(t)$. The social planner will treat $Z(t)$ and $P_{K}(t)$ as exogenously given, while controlling $I_{i}(t)$.

Suppose that $k_{i^{*}}(t)$ and $x_{i}^{*}(t)$ respectively denote the desired capital stock and the maximum amount of waste emissions tolerable by the social planner. When $k(t)>k_{i^{*}}(t)$, the social marginal gain from increasing the abatement capital $v_{2}(\cdot)=\partial V_{2}(\cdot) / \partial k_{i}(t)$, is given by (see Appendix)

$$
v_{2}(\cdot)=F_{2}\left[k_{i}(t)^{a_{0}-1} Z(t)^{a_{0}}\right]^{\beta} P_{K}(t)^{1-\beta}+a_{0} B_{2} k_{i}(t)^{a_{0}-1} Z(t)^{a_{0}} / \phi(1),
$$

where $F_{2}$ is a constant to be determined. Suppose that $k_{i^{*}}(t)$ chosen by the social planner is denoted by $k_{s 2}(t)$. The value-matching and smooth-pasting conditions applied to $v_{2}(\cdot)$ are respectively given by 


$$
\begin{aligned}
v_{2}(\cdot) & =P_{K}(t), \\
\frac{\partial v_{2}(\cdot)}{\partial Z(t)} & =0 .
\end{aligned}
$$

Evaluating both conditions (36) and (37) at $k_{i}(t)=k_{s 2}(t)$, and jointly solving these two equations yields

$$
k_{s 2}(t)=m_{1} k_{f 2}(t) .
$$

Substituting $k_{i}(t)=k_{s 2}(t)$ into equation (14) yields the maximum output level produced by the social planner, denoted by $q_{s 2}(t)$ :

$$
q_{s 2}(t)=A_{2} k_{s 2}(t)^{\frac{\lambda \gamma_{2}}{\left(\lambda \gamma_{1}+h\right)}} Z(t)^{\frac{\lambda \gamma_{2}}{\left(\lambda \gamma_{1}+h\right)}}=m_{2} q_{f 2}(t) .
$$

Substituting both $q_{i}(t)=q_{s 2}(t)$ and $k_{i}(t)=k_{s 2}(t)$ into equation (3) yields the maximum amount of waste emissions tolerable by the social planner, denoted by $x_{s 2}(t)$ :

$$
x_{s 2}(t)=A_{1}^{\gamma_{1}} k_{s 2}(t)^{\frac{-\gamma_{2} h}{\left(\lambda \gamma_{1}+h\right)}} Z(t)^{\frac{-\gamma_{2} h}{\left(\lambda \gamma_{1}+h\right)}}=m_{3} x_{f 2}(t)
$$

\subsection{Policy implications}

The information in this section is summarised in the form of Proposition 1:

Proposition 1: No matter whether capital investment is costlessly reversible or not, a firm will invest at less, produce at less, and pollute at more than the socially efficient levels (Proof: see Appendix).

An individual firm will underestimate the adverse effect of pollution on production. Therefore, it will pollute more than is socially efficient as indicated by Proposition 1. Equivalently, the firm will invest less in abatement capital than is socially efficient. The firm will also produce less than is socially efficient because as indicated by equation (20), investment is positively correlated with the output level.

As the leader, the regulator will anticipate and thus correct the result stated in Proposition 1 by using either an absolute or a proportional performance standard. While the regulator can set an absolute performance standard at the socially efficient level, he cannot be sure whether the firm will respond by producing at the socially efficient level. By contrast, if the regulator implements a proportional performance standard, he can set it 
equal to the ratio of the socially efficient emission level over the socially efficient output level. This is precisely the efficient proportional performance standard considered in what follows.

I will discuss both cases where absolute and proportional performance standards are imposed at their respective socially efficient levels. Suppose that capital investment is costlessly reversible, and the regulator imposes on each firm an absolute performance standard equal to $x_{f 2}(t)$ in equation (25). Replacing $x_{f 1}^{u}(t)$ in equation (21) by $x_{f 2}(t)$ yields the corresponding stock of capital, denoted by $k_{f 1}^{a}(t)$ :

$$
k_{f 1}^{a}(t)=m_{k} k_{f 2}(t)
$$

where $m_{k}=\left[\left(1+\lambda \gamma_{1}\right)\left(1-\frac{h}{N}\right)\left(1+\frac{\lambda \gamma_{1}}{N}\right)^{-1}(1-h)^{-1}\right]^{\frac{\gamma_{1}}{\gamma_{2} h}}>1$. Replacing $k_{f 1}^{u}(t)$ in equation (20) by $k_{f 1}^{a}(t)$ yields the corresponding output level, denoted by $q_{f 1}^{a}(t)$ :

$$
q_{f 1}^{a}(t)=m_{q} q_{f 2}(t), \text { where } m_{q}=m_{k}^{\frac{\gamma_{2}}{\gamma_{1}}}>1
$$

Consider the case where capital investment is completely irreversible, and the regulator imposes on each firm an absolute performance standard equal to $x_{s 2}(t)$ in equation (40). Replacing $x_{s 1}^{u}(t)$ in equation (33) by $x_{s 2}(t)$ yields the corresponding stock of capital, denoted by $k_{s 1}^{a}(t)$ :

$$
k_{s 1}^{a}(t)=m_{k} k_{s 2}(t)
$$

Replacing $k_{s 1}^{u}(t)$ in equation (41) by $k_{s 1}^{a}(t)$ yields the corresponding output level, denoted by $q_{s 1}^{a}(t)$ :

$$
q_{s 1}^{a}(t)=m_{q} q_{s 2}(t)
$$

Given the emission function equation (3), a firm that underestimates the externality from pollution will underestimate both the beneficial effect of abatement capital in reducing pollution, and the adverse effect of production in raising pollution. This yields the result stated in Proposition 2:

Proposition 2: No matter whether capital investment is costlessly reversible or not, if the regulator restricts pollution at the socially efficient level, then a firm will over-invest and over-produce (Proof: see Appendix). 
Let us switch to the case where the regulator imposes on each firm a proportional performance standard, which is defined as the permissible emission per unit output (Montero 2002; Verdier 1995). Define $y_{f 1}^{u}(t)=x_{f 1}^{u}(t) / q_{f 1}^{u}(t)$, and $y_{f 2}(t)=x_{f 2}(t) / q_{f 2}(t)$. Suppose that capital investment is costlessly reversible, and that the regulator imposes on each firm a proportional performance standard equal to $y_{f 2}(t)$. Equating $y_{f 2}(t)$ and $y_{f 1}^{u}(t)$ yields the choice of capital stock with regulation, denoted by $k_{f 1}^{p}(t)$, as given by

$$
k_{f 1}^{p}(t)=m_{k}^{\frac{h\left(\gamma_{1}-1\right)}{(\lambda+h) \gamma_{1}}} k_{f 2}(t) .
$$

Replacing $k_{f 1}^{u}(t)$ in equation (20) and equation (21) by $k_{f 1}^{p}(t)$ yields the corresponding output and emission levels, denoted by $q_{f 1}^{p}(t)$ and $x_{f 1}^{p}(t)$, respectively:

$$
\begin{aligned}
& q_{f 1}^{p}(t)=m_{q}^{\frac{h}{(\lambda+h)}} q_{f 2}(t), \\
& x_{f 1}^{p}(t)=m_{q}^{\frac{h}{(\lambda+h)}} x_{f 2}(t) .
\end{aligned}
$$

Define $y_{s 1}^{u}(t)=x_{s 1}^{u}(t) / q_{s 1}^{u}(t)$, and $y_{s 2}(t)=x_{s 2}(t) / q_{s 2}(t)$. Suppose that capital investment is irreversible and that the regulator imposes on each firm a proportional performance standard equal to $y_{s 2}(t)$. Equating $y_{s 2}(t)$ and $y_{s 1}^{u}(t)$ yields the desired capital stock with regulation, denoted by $k_{s 1}^{p}(t)$ :

$$
k_{s 1}^{p}(t)=m_{k}^{\frac{h\left(\gamma_{1}-1\right)}{(\lambda+h) \gamma_{1}}} k_{s 2}(t)
$$

Replacing $k_{s 1}^{u}(t)$ in equation (32) and equation (33) by $k_{s 1}^{p}(t)$ yields the corresponding output and emission levels, denoted by $q_{s 1}^{p}(t)$ and $x_{s 1}^{p}(t)$, respectively:

$$
\begin{aligned}
& q_{s 1}^{p}(t)=m_{q}^{\frac{h}{(\lambda+h)}} q_{s 2}(t), \\
& x_{s 1}^{p}(t)=m_{q}^{\frac{h}{(\lambda+h)}} x_{s 2}(t) .
\end{aligned}
$$

Pooling all above information yields the results stated in Propositions 3 and 4:

Proposition 3: Suppose that the regulator imposes on a firm a proportional performance standard at the socially efficient level. No matter whether investment is costlessly reversible or not, the firm will over-produce and over-pollute. The firm will also over-invest (under-invest) if emission is increasing with output at an increasing (a decreasing) rate (Proof: see Appendix). 
Proposition 4: No matter whether investment is costlessly reversible or not, a firm will invest more, produce more, and pollute less if the regulator implements an efficient absolute performance standard as compared to the case where the regulator implements an efficient proportional performance standard (Proof: see Appendix).

The reason behind Proposition 4 follows from Proposition 2. Proposition 2 indicates that a regulator who imposes on a firm an absolute performance standard at the socially efficient level will induce the firm to produce at more than the socially efficient level. The emission-output ratio will thus be lower than is socially efficient. This indicates that abatement capital is employed (and thus output is produced) at a level which is beyond the level that keeps the emission-output ratio at the socially efficient level. If, instead, the regulator sets a proportional performance standard at the socially efficient level, then the firm will invest and produce less, and thus pollute more as compared to the case where the regulator sets an efficient absolute performance standard.

Proposition 4, however, does not rank absolute and proportional performance standards. As indicated by Proposition 2, given environmental externalities a firm will not produce and pollute at the socially efficient level. These two inefficiencies should be corrected by implementing two instruments together, for example, effluent taxes and performance standards. The use of either an absolute performance standard or a proportional performance standard will induce the firm to over-pollute as well as overproduce, as indicated by Propositions 2 and 3, respectively.

Finally, I will investigate how various factors such as uncertainty $(\sigma)$, costly expandability $(\mu)$, and competitive pressure $(N)$ affect the regulated performance standards. Some important results are stated in Proposition 5:

Proposition 5: (a) Suppose that investment is costlessly reversible and it is more costly to purchase capital in the future ( $\mu$ is increased). The regulator should then implement a more stringent absolute performance standard, which induces a firm to invest and produce more. The regulator should then also implement a more stringent proportional performance standard, which induces a firm to invest and produce more, and to pollute less. (b) Suppose that investment is irreversible and uncertainty becomes greater ( $\sigma$ is increased). The regulator should then implement a less stringent absolute performance standard, which induces a firm to invest and produce less. The regulator should then also implement a less stringent proportional performance standard, which induces a firm to invest and produce less, and to pollute more. (c) Suppose that competition becomes more intense ( $N$ is increased) whether investment is costlessly reversible or not. The regulator should then implement a more stringent absolute performance 
standard provided that $\gamma_{1}>\gamma_{2}$, which induces a firm to have ambiguous attitudes toward investment and output decisions. The regulator should then also implement a more stringent proportional performance standard provided that $\gamma_{1}>1+\gamma_{2}$, which induces a firm to have ambiguous attitudes toward investment, output, and polluting decisions (Proof: see Appendix).

The reason behind Proposition 5(a) is as follows. Suppose that it is more costly to purchase capital at a later date. As indicated by equation (70), when investment in abatement capital is costlessly reversible, a social planner will then employ more capital and therefore pollute less. Consequently, the regulator should set more stringent absolute and proportional performance standards. However, as investment becomes irreversible, an offsetting effect will arise (see equation (75)) and, therefore, it becomes ambiguous whether the regulator should implement a more stringent policy.

The results of Proposition 5(a) entail policy implications. Suppose that capital investment is almost costlessly reversible. Proposition 5(a) then indicates that the regulator should set a much more stringent standard (at least in terms of the adjustment period) when the expected cost of meeting a standard rises. Consequently, older and newer firms should be treated differently with newer firms getting preferential treatment. However, in practice, older firms rather than newer firms receive preferential treatment. Such a policy, which may be justified if investment is irreversible, usually worsens pollution by encouraging firms to keep old, dirtier plants in operation (Keohane et al. 1998).

The reason behind Proposition 5(b) is as follows. As indicated by equation (79), when investment is irreversible, a social planner will employ less capital and thus pollute more as uncertainty becomes greater. Accordingly, the regulator should be less stringent in implementing absolute and proportional performance standard policies, as indicated by equation (74) and equation (95), respectively. The firm will then be induced to invest and to produce less, as indicated by equation (81) and equation (88) for the former policy, and by equation (100) and equation (105) for the latter policy.

The policy implication of Proposition 5(b) is as follows. The so-called high-tech industries usually invest in an environment that is more volatile than the traditional industries. As a result, the regulator should favour hightech industries when designing performance standard policies.

The reason behind Proposition 5(c) is as follows. Consider the situation that competition becomes more severe. If the adverse effect of production in raising pollution outweighs the beneficial effect of abatement capital in reducing pollution; that is, $\gamma_{1}>\gamma_{2}$, then a social planner will pollute less (see equation (71) and equation (76) no matter whether investment is irreversible or not. Therefore, the regulator should set a more stringent absolute performance standard. The regulator could also set a more stringent proportional 
performance standard if the adverse effect is sufficiently larger than the beneficial effect; that is, $\gamma_{1}>1+\gamma_{2}$, as indicated by equation (92).

The result of Proposition 5(c) indicates that whether the regulator should implement a performance standard policy that favours certain industries depends on the efficiency of abatement capital employed by firms in this industry. For example, suppose that firms in two industries employ the same kind of abatement capital and suppose that $\gamma_{1}>\gamma_{2}\left(\gamma_{1}>1+\gamma_{2}\right)$, then the regulator should implement a more stringent absolute (proportional) performance standard policy for the industry that is more competitive. ${ }^{11}$

\subsection{Numerical examples}

In this section I make the theoretical results more meaningful through numerical examples. The benchmark parameter values are chosen as follows: $Z(t)=1, \lambda=0.1, \sigma=20$ per cent per year, $\gamma_{1}=1, \gamma_{2}=0.5, \varepsilon=3, N=500, \mu=0$ per year, $w=0.5, \rho=5$ per cent per year, and $P_{k}(t)=1 .{ }^{12}$ For ease of exposition, I only present the results for the case where abatement investment is completely irreversible. Given these benchmark parameter values, I find that the absolute performance standard that is socially efficient is given by $x_{s 2}(t)=0.1309$, and the desired capital stock, and the output level induced by it are respectively given by $k_{s 1}^{a}(t)=0.0503$, and $q_{s 1}^{a}(t)=0.0294$. The proportional performance standard that is socially efficient is given by $y_{s 2}(t)=19.968$, and the maximum level of pollution, the desired capital stock, and the maximum level of output induced by it are respectively given by $x_{s 1}^{p}(t)=0.4149, k_{s 1}^{p}(t)=0.0025$, and $q_{s 1}^{p}(t)=0.0208$. These results confirm the results of Proposition 4 indicating that an absolute performance standard policy will induce a firm to invest and produce more, and pollute less as compared to a proportional performance standard policy. I also investigate the responses in these seven endogenous variables to a change of $\sigma$ around the region $(0,40$ per cent), $\mu$ around the region ( -1 per cent, 1 per cent), and $N$ around the region $(400,600)$, holding the other parameters at their benchmark values. These responses are respectively shown in figures $1-3 .{ }^{13}$

11 It is interesting to investigate whether the regulator should favor new abatement capital that is more efficient (higher $\gamma_{2}$ ). However, our comparative-statics results regarding this issue yield ambiguous results (not shown in the Appendix).

12 As suggested by Dixit (1989), some capital costs arise from depreciation and are more thought of as recurrent, and some costs are recoverable when disinvestment occurs. Accordingly, a ratio of $w: \rho P_{K}=10: 1$ seems plausible.

13 For ease of exposition, I scale down $y_{s 2}(t)$ by a factor of 100 , and scale up all $k_{s 1}^{a}(t)$, $k_{s 1}^{p}(t), q_{s 1}^{a}(t)$, and $q_{s 1}^{p}(t)$ by a factor of 10 . 


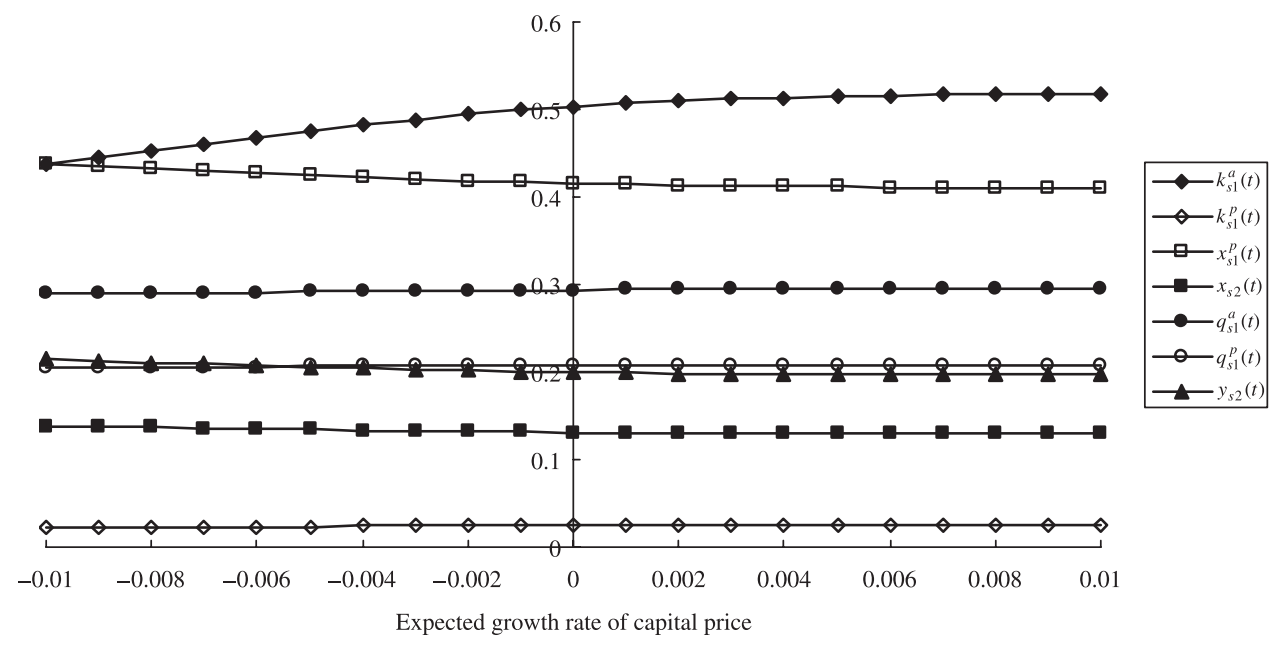

Figure 1 The impact of a change in $\mu$.

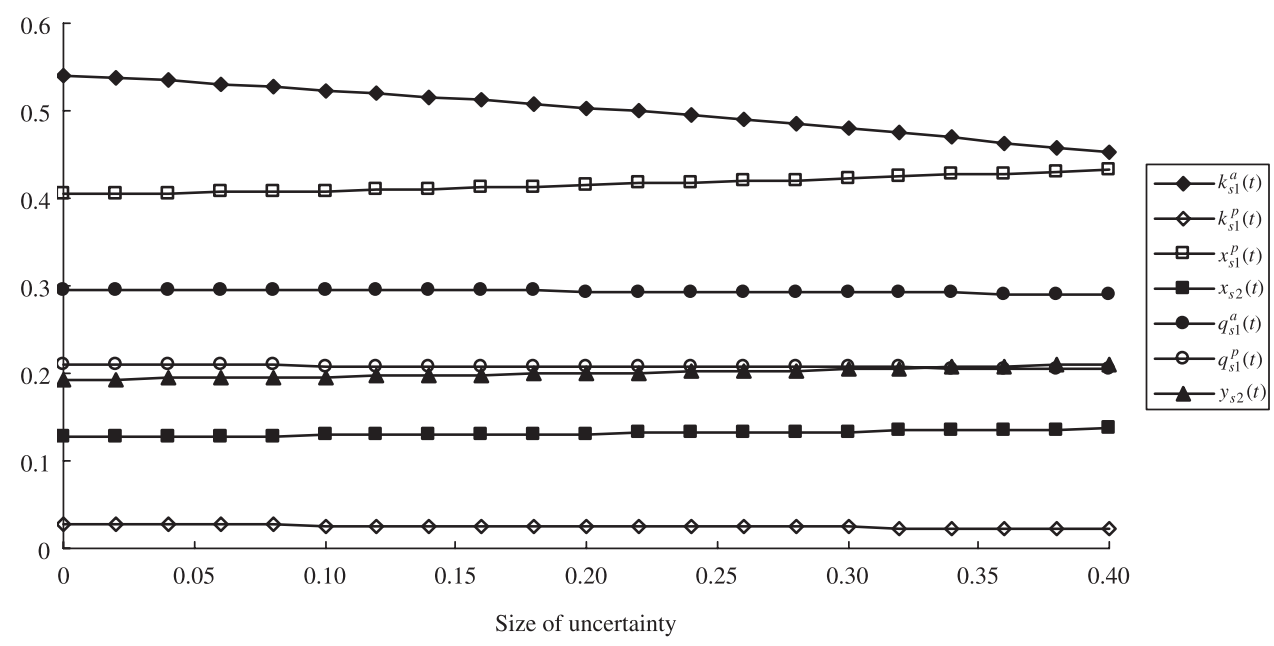

Figure 2 The impact of a change in $\sigma$.

All results shown in figures 1-3 conform to those stated in Proposition 5. Figure 1 indicates that as capital investment is more costly to expand later, the regulator should be more stringent in both absolute and proportional performance standard policies toward irreversible investments. In response, a firm will invest and produce more. Figure 2 shows that as uncertainty becomes greater, the regulator should be more lenient in both policies toward irreversible investments, a finding that is in line with Jou (2001) that 


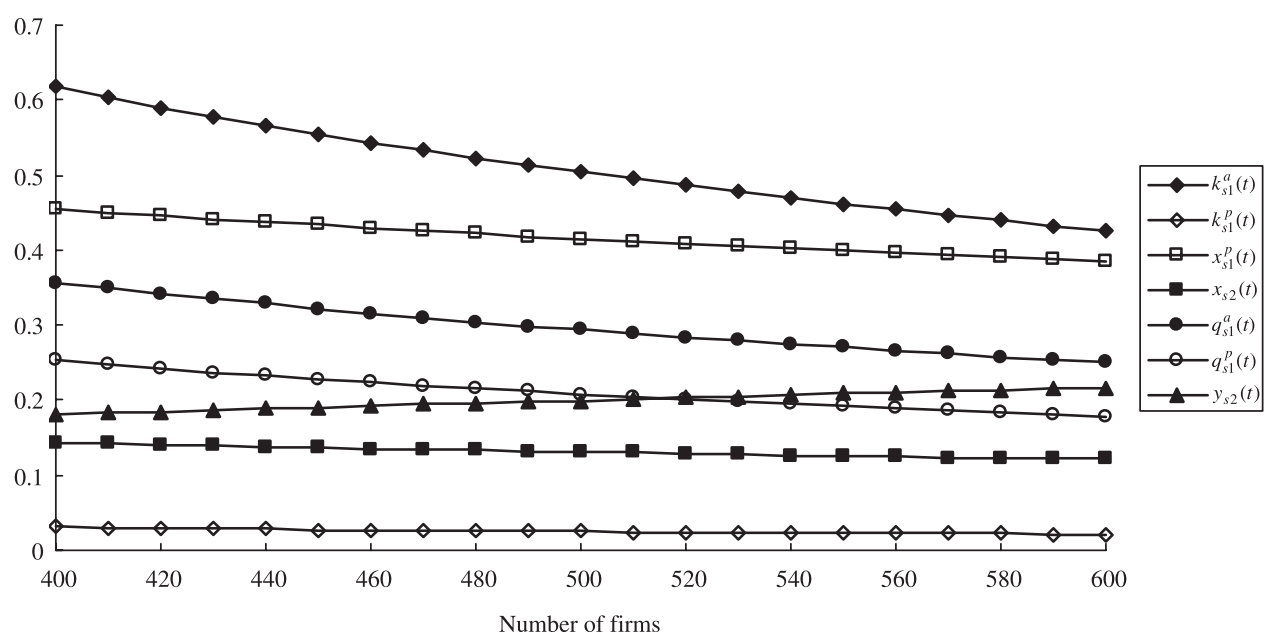

Figure 3 The impact of a change in $N$.

investigates the optimal effluent fee policy. In response, a firm will be less willing both to invest and produce. Finally, figure 3 indicates that as competition becomes more intense, the regulator should impose a more stringent absolute performance standard policy because $\gamma_{1}>\gamma_{2}$ (see Proposition 5(c)), but should implement a less stringent proportional performance standard policy because the constraint $\gamma_{1}>1+\gamma_{2}$ stated in Proposition 5(c) is not satisfied. In response, a firm will invest and produce less.

\section{Conclusion}

The present article investigates the use of performance standards to correct environmental externalities. Each firm in an industry emits waste in the production process, and, in turn, the average waste emissions of an industry adversely affect the firm's productivity. The firm, which incurs sunk costs when employing capital to abate waste emissions, is uncertain about the efficiency of capital. The firm will underestimate environmental externalities, and therefore, it will pollute more than is socially efficient. To correct this tendency, the regulator can set a limit on either emissions or the emissionoutput ratio at the socially efficient level. The firm will invest more, produce more, and pollute less when the regulator implements the former limit than when the regulator implements the latter limit.

The present article has abstracted from several features that may be allowed in future research. First, it ignores both the adverse effect of pollution on the welfare of consumers and spatial distribution of firms. Second, it ignores the costs associated with implementing performance standards. It 
is worth investigating whether the conclusion of the present article will be affected when taking these two features into account.

\section{References}

Ballard, C.L. and Medema, S.G. 1993, 'The marginal efficiency effects of taxes and subsidies in the presence of externalities', Journal of Public Economics, vol. 52, pp. 103-125.

Barbera, A.J. and McConnell, V.D. 1986, 'Effects of pollution control on industry productivity: a factor demand approach', Journal of Industrial Economics, vol. 35, pp. 161-172.

Bertola, G. and Caballero, R.J. 1994, 'Irreversibility and Aggregate Investment', Review of Economic Studies, vol. 61, pp. 223-246.

Clark, C.W., Clarke, F.K. and Munro, G.R. 1979, 'The optimal exploitation of renewable resource stocks: problems of irreversible investment', Econometrica, vol. 47, pp. 25-48.

Cropper, M.L. and Oates, E.W. 1992, 'Environmental economics: a survey', Journal of Economic Literature, vol. 30, pp. 675-740.

Dixit, A.K. 1989, 'Entry and exit decisions under uncertainty', Journal of Political Economy, vol. 97 , pp. $620-638$.

Dixit, A.K. 1991, 'Irreversible investment with price ceilings', Journal of Political Economy, vol. 99 , pp. 541-557.

Dixit, A.K. 1997, 'Investment and employment dynamics in the short run and the long run', Oxford Economic Papers, vol. 49, pp. 1-20.

Dixit, A.K. and Pindyck, R.S. 1994, 'Investment under Uncertainty', Princeton University Press, Princeton, New Jersey.

Dixit, A.K. and Pindyck, R.S. 1998, 'Expandability, reversibility, and optimal capacity choice', working paper no. 6373, National Bureau of Economic Research, Cambridge, MA.

Dixit, A.K. and Rob, R. 1994, 'Switching costs and sectoral adjustments in general equilibrium with uninsured risk', Journal of Economic Theory, vol. 62, pp. 48-69.

Farzin, Y.H. 1996, 'Optimal pricing of environmental and natural resource use with stock externalities', Journal of Public Economics, vol. 62, pp. 31-57.

Fatas, A. and Metrick, A. 1997, 'Irreversible investment and strategic interaction', Economica, vol. 64, pp. 31-47.

Gaudet, G., Lasserre, P. and Long, N.V. 1998, 'Real investment decisions under adjustment costs and asymmetric information', Journal of Economic Dynamics and Control, vol. 23, pp. 71-95.

Gomboso, J., Hertzler, G. and Ghassemi, F. 1999, 'Salinity management: coupling physical and economic modelling approaches', in Mahendrarajah S., Jakeman A.J. and McAleer M.J. (eds), Modelling Change in Integrated Economic and Environmental Systems, John Wiley \& Sons, New York.

Gray, W.B. and Shadbegian, R.J. 1995, 'Pollution abatement costs, regulation, and plant-level productivity', working paper no. 4994, National Bureau of Economic Research, Cambridge, MA.

Gray, W.B. and Shadbegian, R.J. 1998, 'Environmental regulation, investment timing, and technology choice', Journal of Industrial Economics, vol. 46, pp. 235-256.

Grenadier, S.R. 2002, 'Option exercise games: an application to the equilibrium investment strategies of firms', Review of Financial Studies, vol. 15, pp. 691-721.

Hassett, A.K. and Metcalf, G.E. 1992, 'Energy tax credits and residential conservation investment', working paper no. 4020, National Bureau of Economic Research, Cambridge, MA.

Haurie, A. and Krawczyk, J.B. 1997, 'Optimal charges on river effluent from lumped and distributed sources', Environmental Modeling and Assessment, vol. 2, pp. 93-106. 
Haurie, A. and Zaccour, G. 1995, 'Differential game models of global environmental management', Control and Game-Theoretic Models of the Environment. Annals of the International Society of Dynamic Games, vol. 2, pp. 3-23.

Jorgenson, D.W. 1963, 'Capital theory and investment behavior', American Economic Review, vol. 53 , pp. $247-259$.

Jou, J-B. 2001, 'Environment, asset characteristics, and optimal effluent fees', Environmental and Resource Economics, vol. 20, pp. 27-39.

Jou, J-B. and Lee, T. 2001, 'R\&D investment decision and optimal subsidy', $R \& D$ Management, vol. 31, pp. 137-148.

Jung, C., Krutilla, K. and Boyd, R. 1996, 'Incentives for advanced pollution abatement technology at the industry level: an evaluation of policy alternatives', Journal of Environmental Economics and Management, vol. 30, pp. 95-111.

Keohane, N., Revesz, R. and Stavins, R.N. 1998, 'The choice of regulatory instruments in environmental policy', Harvard Environmental Review, pp. 313-367.

Kolstad, C.D. 1996, 'Learning and stock effects in environmental regulations: the case of greenhouse gas emissions', Journal of Environmental Economics and Management, vol. 31, pp. $1-18$.

Kolstad, C.D. 2000, 'Environmental Economics', Oxford University Press.

Kort, P.M. 1996, 'Pollution-control and the dynamics of the firm- the effects of market-based instruments on optimal firm investments', Optimal Control Applications and Methods, vol. 17 , pp. $267-279$.

Krawczyk, J.B. 1995, 'Management of effluent discharges: a dynamic game model', Control and Game-Theoretic Models of the Environment. Annals of the International Society of Dynamic Games, vol. 2, pp. 336-356.

Krawczyk, J.B. and Zaccour, G. 1999, 'Management of pollution from decentralized agents by local government', International Journal of Environment and Pollution, vol. 12, pp. 343-357.

Mohtadi, H. 1996, 'Environment, growth, and optimal policy design', Journal of Public Economics, vol. 63, pp. 199-140.

Montero, J-P. 2002, 'Permits, standards, and technology innovation', Journal of Environmental Economics and Management, vol. 44, pp. 23-44.

Pindyck, R.S. 1988, 'Irreversible investment, capacity choice, and the value of the firm', American Economic Review, vol. 78, pp. 969-985.

Pindyck, R.S. 2000, 'Irreversibilities and the timing of environmental policy', Resource and Energy Economics, vol. 22, pp. 233-259.

Pindyck, R.S. 2002, 'Optimal timing problems in environmental economics', Journal of Economic Dynamics and Control, vol. 26, pp. 1677-1697.

Requate, T. and Unold, W. 2003, 'Environmental policy incentives to adopt advanced abatement technology: will the true ranking please stand up', European Economic Review, vol. 47, pp. $125-146$.

Roberts, M.J. and Spence, M. 1976, 'Effluent charges and licenses under uncertainty', Journal of Public Economics, vol. 5, pp. 193-208.

Rosen, J.B. 1965, 'Existence and uniqueness of equilibrium points for concave N-person games', Econometrica, vol. 33, pp. 520-534.

Saphores, J.M. and Carr, P. 1999, 'Pollution reduction, environmental uncertainty, and the irreversibility effect', $3^{\text {rd }}$ Annual international conference on real options: theory meets practice, Wassenaar/Leiden, The Netherlands.

Stavins, R.N. 2000, 'Market-based Environmental Policies', in Portney P.R. and Stavins R.N. (eds), Public Policies for Environmental Protection, $2^{\text {nd }}$ Edition, Resource for the Future, Washington, DC. 
Tietenberg, T. 1992, Environmental and Natural Resource Economics, $3^{\text {rd }}$ Edition, Harper Collins Publishers, New York.

Verdier, T. 1995, 'Environmental pollution and endogenous growth: a comparison between emission taxes and technological standards', Control and Game-Theoretic Models of the Environment. Annals of the International Society of Dynamic Games, vol. 2, pp. 175-200.

Weitzman, M.L. 1974, 'Prices vs. quantities', Review of Economic Studies, vol. 41, pp. 477-491.

Xepapadeas, A. 1999, 'Environmental policy and firm behavior: abatement investment and location decisions under uncertainty and irreversibility', technical working paper, no. 243, National Bureau of Economic Research, Cambridge, MA.

\section{Appendix}

\section{Derivation of $v_{1}(\cdot)$ and $v_{2}(\cdot)$}

Consider the problem of choosing $I_{i}(t)$ such that equation (26) is maximised. The Bellman-Hamiton-Jacobi for this problem can be written as

$$
\rho V_{1}(\cdot)=\max _{\left\{I_{i}(t)\right\}}\left\{\pi^{1}[k(t), Z(t)]-P_{K}(t) I_{i}(t)+\frac{1}{d t} E_{t} d V_{1}(\cdot)\right\} .
$$

Equation (51) says that the total return on this asset, $\rho V_{1}(\cdot)$ has two components, the cash flow $\pi^{1}(k(t), Z(t))-P_{K}(t) I_{i}(t)$, and the expected rate of capital gain, $\frac{1}{d t} E_{t} d V_{1}(\cdot)$, where

$$
E_{t} \frac{d V_{1}(\cdot)}{d t}=\frac{1}{2} \sigma^{2} Z(t)^{2} \frac{\partial^{2} V_{1}(\cdot)}{\partial Z(t)^{2}}+\mu P_{K}(t) \frac{\partial V_{1}(\cdot)}{\partial P_{K}(t)}+I_{i}(t) \frac{\partial V_{1}(\cdot)}{\partial k_{i}(t)},
$$

by using both equations (4) and (11), and by applying Itô's Lemma. Differentiating the right-hand side of equation (51) with respect to $I_{i}(t)$, and then setting the result equal to zero yields

$$
\frac{\partial V_{1}(\cdot)}{\partial k_{i}(t)}=P_{K}(t)
$$

Substituting $\pi_{i}^{1}(\cdot)$ given by equation (17) and $\frac{1}{d t} E_{t} d V_{1}(\cdot)$ in equation (52) into equation (51), and using the condition in equation (53) yields the differential equation

$$
\frac{1}{2} \sigma^{2} Z(t)^{2} \frac{\partial^{2} V_{1}(\cdot)}{\partial Z(t)^{2}}-\rho V_{1}(\cdot)+\mu P_{K}(t) \frac{\partial V_{1}(\cdot)}{\partial P_{K}(t)}+B_{1} G_{1}^{a_{1}} G_{2} \frac{-\left(\lambda \gamma_{1}+1\right)}{\left(\lambda \gamma_{1}+h\right)} G_{3} Z(t)^{a_{0}}=0
$$

Let $\partial V_{1}(\cdot) / \partial k_{i}(t)=v_{1}(\cdot)$. Differentiating equation (54) term by term with respect to $k_{i}(t)$ yields 


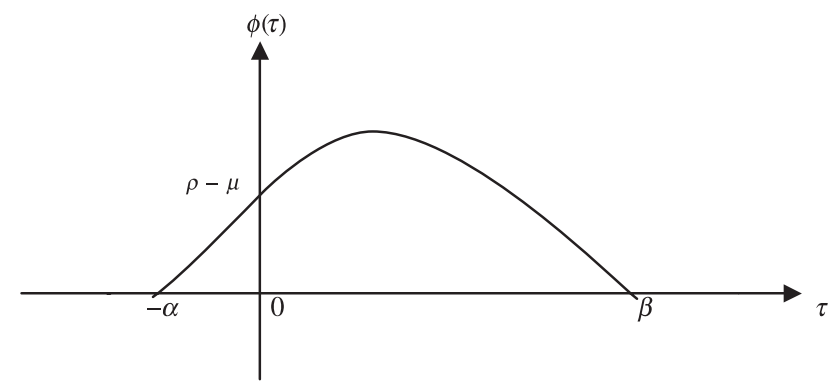

Figure $4 \phi(\tau)$ versus $\tau$.

$$
\frac{1}{2} \sigma^{2} Z(t)^{2} \frac{\partial^{2} v_{1}(\cdot)}{\partial Z(t)^{2}}-\rho v_{1}(\cdot)+\mu P_{K}(t) \frac{\partial v_{1}(\cdot)}{\partial P_{K}(t)}+G Z(t)^{a_{0}}=0,
$$

where $G$ is defined in equation (28). Based on Bertola and Caballero (1994), the term $\left[G Z(t)^{a_{0}}\right]^{\tau} P_{K}(t)^{1-\tau}$ solves the homogeneous part of equation (55). Substituting this into equation (55) yields the quadratic equation

$$
\phi(\tau)=-\frac{1}{2} \sigma^{2} a_{0} \tau\left(a_{0} \tau-1\right)-\mu(1-\tau)+\rho=0 .
$$

Denote $\beta$ and $-\alpha$ respectively as the larger and smaller roots in the quadratic equation given by equation (56). Following Dixit (1991), equation (56) can be rewritten as

$$
\phi(\tau)=-\frac{1}{2} a_{0}^{2} \sigma^{2}(\alpha+\tau)(\beta-\tau)=\frac{(\rho-\mu)(\alpha+\tau)(\beta-\tau)}{\alpha \beta},
$$

where $\phi(\tau)>0$ if $-\alpha<\tau<\beta$. Figure 4 depicts $\phi(\tau)$ as a function of $\tau$.

One particular solution from the non-homogeneous part of equation (55) is given by

$$
v_{1}(\cdot)=G Z(t)^{a_{0}} / \phi(1) .
$$

Since the value function $V_{1}(\cdot)$ must approach zero as $Z(t)$ approaches zero, only the positive root in equation (56) should be considered. The general solution of equation (55), which is composed of solutions from both the homogeneous and non-homogeneous parts, is shown by equation (28).

Similarly, the Bellman-Hamiton-Jacobi equation for the problem described in equation (34) can be written as

$$
\rho V_{2}(\cdot)=\max _{\left\{I_{i}(t)\right\}}\left\{\pi^{2}\left[k_{i}(t), Z(t)\right]-P_{K}(t) I_{i}(t)+\frac{1}{d t} E_{t} d V_{2}(\cdot)\right\},
$$


where

$$
E_{t} \frac{d V_{2}(\cdot)}{d t}=\frac{1}{2} \sigma^{2} Z(t)^{2} \frac{\partial^{2} V_{2}(\cdot)}{\partial Z(t)^{2}}+\mu P_{K}(t) \frac{\partial V_{2}(\cdot)}{\partial P_{K}(t)}+I_{i}(t) \frac{\partial V_{2}(\cdot)}{\partial k_{i}(t)} .
$$

Differentiating the right-hand side of equation (59) with respect to $I_{i}(t)$, and then setting the result equal to zero yields

$$
\frac{\partial V_{2}(\cdot)}{\partial k_{i}(t)}=P_{K}(t)
$$

Substituting $\pi^{2}(\cdot)$ given by equation (16) and $E_{t}\left[d V_{2}(\cdot) / d t\right]$ in equation (60) into equation (59), and using the condition given by equation (61) yields

$$
\frac{1}{2} \sigma^{2} Z(t)^{2} \frac{\partial^{2} V_{2}(\cdot)}{\partial Z(t)^{2}}-\rho V_{2}(\cdot)+\mu P_{K}(t) \frac{\partial V_{2}(\cdot)}{\partial P_{K}(t)}+B_{2} k_{i}(t)^{a_{0}} Z(t)^{a_{0}}=0 .
$$

Let $\partial V_{2}(\cdot) / \partial k_{i}(t)=v_{2}(\cdot)$. Differentiating equation (62) term by term with respect to $k_{i}(t)$ yields

$$
\frac{1}{2} \sigma^{2} Z(t)^{2} \frac{\partial^{2} v_{2}(\cdot)}{\partial Z(t)^{2}}-\rho v_{2}(\cdot)+\mu P_{K}(t) \frac{\partial v_{2}(\cdot)}{\partial P_{K}(t)}+a_{0} B_{2} k_{i}(t)^{a_{0}-1} Z(t)^{a_{0}}=0
$$

The solution to $v_{2}(\cdot)$ in equation (63) is thus given by equation (35).

\section{Proof of proposition 1}

Dividing $k_{f 1}^{u}(t)$ in equation (19) by $k_{f 2}(t)$ in equation (23) yields

$$
k_{f 1}^{u}(t) / k_{f 2}(t)=\left(\frac{N-h}{1-h}\right)^{\frac{-1}{1-a_{0}}}\left[\left(1+\lambda \gamma_{1}\right)\left(1-\frac{h}{N}\right)\left(1+\frac{\lambda \gamma_{1}}{N}\right)^{-1}(1-h)^{-1}\right]^{\frac{\lambda \gamma_{1}+1}{\left(\lambda \gamma_{1}+h\right)\left(1-a_{0}\right)}}<1,
$$

since if $N=1$ then $k_{f 1}^{u}(t) / k_{f 2}(t)=1$, and differentiating $k_{f 1}^{u}(t) / k_{f 2}(t)$ with respect to $N$ yields a negative sign.

Dividing $x_{f 1}^{u}(t)$ in equation (21) by $x_{f 2}(t)$ in equation (25) yields

$$
x_{f 1}^{u}(t) / x_{f 2}(t)=\left[\left(1+\lambda \gamma_{1}\right)\left(1-\frac{h}{N}\right)\left(1+\frac{\lambda \gamma_{1}}{N}\right)^{-1}(1-h)^{-1}\right]^{\frac{\gamma_{1}}{\left(\lambda \gamma_{1}+h\right)}}\left(\frac{k_{f 1}^{u}(t)}{k_{f 2}(t)}\right)^{\frac{-\gamma_{2} h}{\left(\lambda \gamma_{1}+h\right)}}>1 .
$$


Dividing $k_{s 1}^{u}(t)$ in equation (31) by $k_{s 2}(t)$ in equation (38) yields

$$
k_{s 1}^{u}(t) / k_{s 2}(t)=k_{f 1}^{u}(t) / k_{f 2}(t) .
$$

Dividing $x_{s 1}^{u}(t)$ in equation (33) by $x_{s 2}(t)$ in equation (40) yields

$$
x_{s 1}^{u}(t) / x_{s 2}(t)=x_{f 1}^{u}(t) / x_{f 2}(t) .
$$

Dividing $q_{f 1}^{u}(t)$ in equation (20) by $q_{f 2}(t)$ in equation (24) yields

$$
q_{f 1}^{u}(t) / q_{f 2}(t)=N^{\frac{-\gamma_{2} \lambda}{\left(1-a_{0}\right)\left(\gamma_{1} \lambda+h\right)}}\left[\left(1+\lambda \gamma_{1}\right)\left(1-\frac{h}{N}\right)\left(1+\frac{\lambda \gamma_{1}}{N}\right)^{-1}(1-h)^{-1}\right]^{\frac{1}{\left(\lambda \gamma_{1}+h\right)}\left[1+\frac{\lambda \gamma_{1}+1}{\left(1-a_{0}\right)}\right]}<1,
$$

since if $N=1$ then $q_{f 1}^{u}(t) / q_{f 2}(t)=1$, and (for $N \geq 2$ ) differentiating $q_{f 1}^{u}(t) /$ $q_{f 2}(\mathrm{t})$ with respect to $N$ yields a negative sign.

Dividing $q_{s 1}^{u}(t)$ in equation (32) by $q_{s 2}(t)$ in equation (39) yields

$$
\frac{q_{s 1}^{u}(t)}{q_{s 2}(t)}=\frac{q_{f 1}^{u}(t)}{q_{f 2}(t)}<1
$$

This completes the proof.

\section{Proof of proposition 2}

Proposition 2 follows because $m_{k}>1$ and $m_{q}>1$ such that $k_{f 1}^{a}(t)>k_{f 2}(t)$, $q_{f 1}^{a}(t)>q_{f 2}(t), k_{s 1}^{a}(t)>k_{s 2}(t)$, and $q_{s 1}^{a}(t)>q_{s 2}(t)$.

\section{Proof of proposition 3}

Because $m_{q}^{\frac{h}{(\lambda+h)}}>1$ it follows that $q_{f 1}^{t}(t)>q_{f 2}(t), x_{f 1}^{p}(t)>x_{f 2}(t), q_{s 1}^{p}(t)>q_{s 2}(t)$, and $x_{s 1}^{p}(t)>x_{s 2}(t)$. If $\gamma_{1}<(>) 1$ then $m_{k}^{\frac{h\left(\gamma_{1}-1\right)}{(\lambda+h) \gamma_{1}}}<(>) 1$ and thus $k_{f 1}^{p}(t)<(>) k_{f 2}(t)$ and $k_{s 1}^{p}(t)<(>) k_{s 2}(t)$. This completes the proof.

\section{Proof of proposition 4}

Because $m_{k}>1$ it follows that $k_{f 1}^{p}(t)<k_{f 1}^{a}(t)$ and $k_{s 1}^{p}(t)<k_{s 1}^{a}(t)$. Because $m_{q}>1$, it follows that $q_{f 1}^{p}(t)<q_{f 1}^{a}(t), q_{s 1}^{p}(t)<q_{s 1}^{a}(t), x_{f 1}^{p}(t)<x_{f 2}(t)$ and $x_{s 1}^{p}(t)<x_{s 2}(t)$. This completes the proof. 


\section{Proof of proposition 5}

Differentiating $x_{f 2}(t)$ with respect to $\mu$ and $N$ yields

$\frac{\partial x_{f 2}(t)}{\partial \mu}=\frac{-\gamma_{2} h x_{f 2}(t)}{\left(\lambda \gamma_{1}+h\right) k_{f 2}(t)} \frac{\partial k_{f 2}(t)}{\partial \mu}<0$, where $\frac{\partial k_{f 2}(t)}{\partial \mu}=\frac{k_{f 2}(t)}{\left(1-a_{0}\right)(\rho-\mu)}>0$,

$\frac{\partial x_{f 2}(t)}{\partial N}=\frac{h\left(\gamma_{2}-\gamma_{1}\right)\left(\lambda \gamma_{1}+h\right) x_{f 2}(t)}{N\left(\lambda \gamma_{1}+h\right)\left(\lambda \gamma_{1}+h-\lambda \gamma_{2}(1-h)\right)}$, where $\frac{\partial x_{f 2}(t)}{\partial N}<0$ if $\gamma_{2}<\gamma_{1}$.

Let $X=(1+\alpha) / \alpha>1$ and $Y=\left[\frac{\lambda}{h}\left(h-1+\frac{\gamma_{1}}{\gamma_{2}}\right)+\frac{1}{\gamma_{2}}\right]^{-1}>0$, then $m_{3}=X^{Y}$. Differentiating $m_{3}$ with respect to $\sigma$ and $\mu$ yields

$$
\frac{\partial m_{3}}{\partial \sigma}=\frac{-m_{3} Y}{\alpha(1+\alpha)} \frac{\partial \alpha}{\partial \sigma}>0, \text { where } \frac{\partial \alpha}{\partial \sigma}=\frac{\partial \phi(-\alpha) / \partial \sigma}{\partial \phi(-\alpha) / \partial \tau}<0,
$$

since $\frac{\partial \phi(-\alpha)}{\partial \sigma}=-\sigma\left[a_{0}(-\alpha)\right]\left[a_{0}(-\alpha)-1\right]<0$, and $\frac{\partial \phi(-\alpha)}{\partial \tau}>0$ from figure 4;

$$
\frac{\partial m_{3}}{\partial \mu}=\frac{-m_{3} Y}{\alpha(1+\alpha)} \frac{\partial \alpha}{\partial \mu}>0
$$

where $\frac{\partial \alpha}{\partial \mu}=\frac{\partial \phi(-\alpha) / \partial \mu}{\partial \phi(-\alpha) / \partial \tau}<0$, since $\frac{\partial \phi(-\alpha)}{\partial \mu}=-(1-(-\alpha))<0$.

Differentiating $x_{s 2}(t)$ with respect to $\sigma, \mu$ and $N$ yields

$$
\begin{aligned}
& \frac{\partial x_{s 2}(t)}{\partial \sigma}=x_{f 2}(t) \frac{\partial m_{3}}{\partial \sigma}>0, \\
& \frac{\partial x_{s 2}(t)}{\partial \mu}=m_{3} \frac{\partial x_{f 2}(t)}{\partial \mu}+x_{f 2}(t) \frac{\partial_{m_{3}}}{\partial \mu}, \\
& (-) \\
& \frac{\partial x_{s 2}(t)}{\partial N}=m_{3} \frac{\partial x_{f 2}(t)}{\partial N}, \text { where } \frac{\partial x_{f 2}(t)}{\partial N}<0 \text { if } \gamma_{2}<\gamma_{1} .
\end{aligned}
$$

Differentiating $k_{f 1}^{a}(t)$ with respect to $\mu$ and $N$ yields

$$
\frac{\partial k_{f 1}^{a}(t)}{\partial \mu}=m_{k} \frac{\partial k_{f 2}(t)}{\partial \mu}>0
$$




$$
\frac{\partial k_{f 1}^{a}(t)}{\partial N}=m_{k} \frac{\partial k_{f 2}(t)}{\partial N}+k_{f 2}(t) \frac{\partial m_{k}}{\partial N},
$$

where $\frac{\partial k_{f 2}(t)}{\partial N}=\frac{-h\left(\lambda \gamma_{1}+1\right) k_{f 2}(t)}{\left(1-a_{0}\right)\left(\lambda \gamma_{1}+h\right) N}<0$, and $\frac{\partial m_{k}}{\partial N}=\frac{\gamma_{1}\left(h+\lambda \gamma_{1}\right) m_{k}}{\gamma_{2} h\left(1-\frac{h}{N}\right) N^{2}\left(1+\frac{\lambda \gamma_{1}}{N}\right)}$
$>0$.

Differentiating $m_{1}$ with respect to $\sigma$ and $\mu$ yields

$$
\begin{gathered}
\frac{\partial m_{1}}{\partial \sigma}=\frac{m_{1}}{\left(1-a_{0}\right) \alpha(1+\alpha)} \frac{\partial \alpha}{\partial \sigma}<0, \\
\frac{\partial m_{1}}{\partial \mu}=\frac{m_{1}}{\left(1-a_{0}\right) \alpha(1+\alpha)} \frac{\partial \alpha}{\partial \mu}<0 .
\end{gathered}
$$

Differentiating $k_{s 1}^{a}(t)$ with respect to $\sigma, \mu$ and $N$ yields

$$
\begin{aligned}
& \frac{\partial k_{s 1}^{a}(t)}{\partial \sigma}=k_{f 1}^{a}(t) \frac{\partial m_{1}}{\partial \sigma}<0 \\
& \frac{\partial k_{s 1}^{a}(t)}{\partial \mu}=m_{1} \frac{\partial k_{f 1}^{a}(t)}{\partial \mu}+k_{f 1}^{a}(t) \frac{\partial m}{\partial \sigma} \\
& \frac{\partial k_{s 1}^{a}(t)}{\partial N}=m_{1} \frac{\partial k_{f 1}^{a}(t)}{\partial N}
\end{aligned}
$$

Differentiating $q_{f 1}^{a}(t)$ with respect to $\mu$ and $N$ yields

$$
\begin{gathered}
\frac{\partial q_{f 1}^{a}(t)}{\partial \mu}=\frac{\lambda \gamma_{2} q_{f 1}^{a}(t)}{\left(\lambda \gamma_{1}+h\right) k_{f 2}(t)} \frac{\partial k_{f 2}(t)}{\partial \mu}>0, \\
\frac{\partial q_{f 1}^{a}(t)}{\partial N}=m_{q} \frac{\partial q_{f 2}(t)}{\partial N}+q_{f 2}(t) \frac{\partial m_{q}}{\partial N}, \\
(-)
\end{gathered}
$$

where

$$
\frac{\partial q_{f 2}(t)}{\partial N}=\frac{-h q_{f 2}(t)}{N\left(\lambda \gamma_{1}+h\right)}\left[1+\frac{\lambda \gamma_{2}\left(\lambda \gamma_{1}+1\right)}{\left(1-a_{0}\right)\left(\lambda \gamma_{1}+h\right)}\right]<0, \frac{\partial m_{q}}{\partial N}=\frac{\gamma_{1}}{\gamma_{2}} m_{k}^{\frac{\gamma_{1}}{\gamma_{2}}-1} \frac{\partial m_{k}}{\partial N}>0 .
$$


Let $Z=\left[\frac{\gamma_{1}}{\gamma_{2}}-1+h\left(1+\frac{1}{\lambda \gamma_{2}}\right)\right]^{-1}>0$, then $m_{2}=X^{-Z}$. Differentiating $m_{2}$ with respect to $\sigma$ and $\mu$ yields

$$
\begin{aligned}
& \frac{\partial m_{2}}{\partial \sigma}=\frac{m_{2} Z}{\alpha(1+\alpha)} \frac{\partial \alpha}{\partial \sigma}<0 \\
& \frac{\partial m_{2}}{\partial \mu}=\frac{m_{2} Z}{\alpha(1+\alpha)} \frac{\partial \alpha}{\partial \mu}<0 .
\end{aligned}
$$

Differentiating $q_{s 1}^{a}(t)$ with respect to $\sigma, \mu$ and $N$ yields

$$
\begin{aligned}
& \frac{\partial q_{s 1}^{a}(t)}{\partial \sigma}=q_{f 1}^{a}(t) \frac{\partial m_{2}}{\partial \sigma}<0, \\
& \frac{\partial q_{s 1}^{a}(t)}{\partial \mu}=m_{2} \frac{\partial q_{f 1}^{a}(t)}{\partial \mu}+q_{f 1}^{a}(t) \frac{\partial m_{2}}{\partial \sigma}, \\
& \text { (+) } \\
& \frac{\partial q_{s 1}^{a}(t)}{\partial N}=m_{2} \frac{\partial q_{f 1}^{a}(t)}{\partial N} .
\end{aligned}
$$

Differentiating $y_{f 2}(t)$ with respect to $\mu$ and $N$ yields

$$
\begin{aligned}
& \frac{\partial y_{f 2}(t)}{\partial \mu}=\frac{-\gamma_{2}(\lambda+h)}{\left(\lambda \gamma_{1}+h\right) k_{f 2}(t)} \frac{\partial k_{f 2}(t)}{\partial \mu}<0, \\
& \frac{\partial y_{f 2}(t)}{\partial N}=\frac{-h\left[\left(\lambda \gamma_{1}+h\right)\left(\gamma_{1}-1-\gamma_{2}\right)+\lambda \gamma_{2} h\left(\gamma_{1}-1\right)\right] y_{f 2}(t)}{\left(\lambda \gamma_{1}+h\right)\left(\lambda \gamma_{1}+h-\lambda \gamma_{2}(1-h)\right) N},
\end{aligned}
$$

where $\frac{\partial f_{z}(t)}{\partial N}<0$ if $\gamma_{1}>1+\gamma_{2}$.

Define $m_{4}=m_{2} / m_{3}=m_{3}^{1+\frac{\lambda}{h}}$, then $y_{s 2}(t)=m_{4} y_{s 2}(t)$. Differentiating $m_{4}$ with respect to $\sigma$ and $\mu$ yields

$$
\frac{\partial m_{4}}{\partial \sigma}=\left(1+\frac{\lambda}{h}\right) \frac{m_{4}}{m_{3}} \frac{\partial m_{3}}{\partial \sigma}>0
$$


Environment, irreversibility, and optimal effluent standards

$$
\frac{\partial m_{4}}{\partial \mu}=\left(1+\frac{\lambda}{h}\right) \frac{m_{4}}{m_{3}} \frac{\partial m_{3}}{\partial \mu}>0 .
$$

Differentiating $y_{s 2}(t)$ with respect to $\sigma, \mu$, and $N$ yields

$$
\begin{aligned}
& \frac{\partial y_{s 2}(t)}{\partial \sigma}=y_{f 2}(t) \frac{\partial m_{4}}{\partial \sigma}>0, \\
& \frac{\partial y_{s 2}(t)}{\partial \mu}=m_{4} \frac{\partial y_{f 2}(t)}{\partial \mu}+y_{f 2}(t) \frac{\partial m_{4}}{\partial \mu}, \\
& (-) \\
& \frac{\partial y_{s 2}(t)}{\partial N}=m_{4} \frac{\partial y_{f 2}(t)}{\partial N} .
\end{aligned}
$$

Differentiating $k_{f 1}^{p}(t)$ with respect to $\mu$ and $N$ yields

$$
\begin{aligned}
& \frac{\partial k_{f 1}^{p}(t)}{\partial \mu}=m_{k}^{\frac{h\left(\gamma_{1}-1\right)}{(\lambda+h) \gamma_{1}}} \frac{\partial k_{f 2}(t)}{\partial \mu}>0, \\
& \frac{\partial k_{f 1}^{p}(t)}{\partial N}=m_{k}^{\frac{h\left(\gamma_{1}-1\right)}{(\lambda+h) \gamma_{1}}} \frac{\partial k_{f 2}(t)}{\partial N}+k_{f 1}^{p}(t) \frac{h\left(\gamma_{1}-1\right)}{(\lambda+h) \gamma_{1} m_{k}} \frac{\partial m_{k}}{\partial N} . \\
& (-)
\end{aligned}
$$

Differentiating $k_{s 1}^{p}(t)$ with respect to $\sigma, \mu$, and $N$ yields

$$
\begin{aligned}
& \frac{\partial k_{s 1}^{p}(t)}{\partial \sigma}=m_{k}^{\frac{h\left(\gamma_{1}-1\right)}{(\lambda+h) \gamma_{1}}} \frac{\partial k_{s 2}(t)}{\partial \sigma}<0, \\
& \frac{\partial k_{s 1}^{p}(t)}{\partial \mu}=m_{k}^{\frac{h\left(\gamma_{1}-1\right)}{(\lambda+h) \gamma_{1}}} \frac{\partial k_{s 2}(t)}{\partial \mu}>0, \\
& \frac{\partial k_{s 1}^{p}(t)}{\partial N}=m_{k}^{\frac{h\left(\gamma_{1}-1\right)}{(\lambda+h) \gamma_{1}}} \frac{\partial k_{s 2}(t)}{\partial N}+k_{s 1}^{p}(t) \frac{h\left(\gamma_{1}-1\right)}{(\lambda+h) \gamma_{1} m_{k}} \frac{\partial m_{k}}{\partial N} . \\
& (-)
\end{aligned}
$$

Differentiating $q_{f 1}^{p}(t)$ with respect to $\mu$ and $N$ yields

$$
\frac{\partial q_{f 1}^{p}(t)}{\partial \mu}=m_{q}^{\frac{h}{(\lambda+h)}} \frac{\partial q_{f 2}(t)}{\partial \mu}>0
$$




$$
\frac{\partial q_{f 1}^{p}(t)}{\partial N}=m_{q}^{\frac{h}{(\lambda+h)}} \frac{\partial q_{f 2}(t)}{\partial N}+q_{f 2}(t) \frac{h}{(\lambda+h)} m_{q}^{\frac{h}{(\lambda+h)}-1} \frac{\partial m_{q}}{\partial N} .
$$

Differentiating $q_{s 1}^{p}(t)$ with respect to $\sigma, \mu$ and $N$ yields

$$
\begin{aligned}
& \frac{\partial q_{s 1}^{p}(t)}{\partial \sigma}=q_{f 1}^{p}(t) \frac{\partial m_{2}}{\partial \sigma}<0, \\
& \frac{\partial q_{s 1}^{p}(t)}{\partial \mu}=m_{2} \frac{\partial q_{f 1}^{p}(t)}{\partial \mu}+q_{f 1}^{p}(t) \frac{\partial m_{2}}{\partial \sigma}, \\
& \text { (+) (-) } \\
& \frac{\partial q_{s 1}^{p}(t)}{\partial N}=m_{2} \frac{\partial q_{f 1}^{p}(t)}{\partial N} .
\end{aligned}
$$

Differentiating $x_{f 1}^{p}(t)$ with respect to $\mu$ and $N$ yields

$$
\begin{aligned}
& \frac{\partial x_{f 1}^{p}(t)}{\partial \mu}=m_{q}^{\frac{h}{(\lambda+h)}} \frac{\partial x_{f 2}(t)}{\partial \mu}<0, \\
& \frac{\partial x_{f 1}^{p}(t)}{\partial N}=\frac{h}{(\lambda+h)} m_{q}^{\frac{h}{(\lambda+h)}}-1 \frac{\partial m_{q}}{\partial N} x_{f 2}(t)+m_{q}^{\frac{h}{(\lambda+h)}} \frac{\partial x_{f 2}(t)}{\partial N} .
\end{aligned}
$$

Differentiating $x_{s 1}^{p}(t)$ with respect to $\sigma, \mu$ and $N$ yields

$$
\begin{aligned}
& \frac{\partial x_{s 1}^{p}(t)}{\partial \sigma}=m_{q}^{\frac{h}{(\lambda+h)}} \frac{\partial x_{s 2}(t)}{\partial \sigma}>0, \\
& \frac{\partial x_{s 1}^{p}(t)}{\partial \mu}=m_{q}^{\frac{h}{(\lambda+h)}} \frac{\partial x_{s 2}(t)}{\partial \mu}, \\
& \frac{\partial x_{s 1}^{p}(t)}{\partial N}=\frac{h}{(\lambda+h)} m_{q}^{\frac{h}{(\lambda+h)}}-1 \frac{\partial m_{q}}{\partial N} x_{s 2}(t)+m_{q}^{\frac{h}{(\lambda+h)}} \frac{\partial x_{s 2}(t)}{\partial N} . \\
& \text { (+) }
\end{aligned}
$$

